\title{
AC 2010-997: GENDER REPRESENTATION IN ARCHITECTURAL ENGINEERING - IS IT ALL IN THE NAME?
}

\section{Pamalee Brady, California Polytechnic State University}

Pamalee A. Brady is an Associate Professor in the Architectural Engineering Department at California Polytechnic State University in San Luis Obispo. She is a registered Professional Engineer in California. Pamalee Brady received a B.S. degree in Architectural Engineering from Cal Poly, M.S. in Civil Engineering from UC Berkeley and a Ph.D. degree in Civil Engineering with a concentration in Structural Engineering from the University of Illinois. Her research interests focus on engineering education incorporating forensic engineering and STEM education for K-12 students.

\section{Allen Estes, California Polytechnic State University}

Allen C. Estes is a Professor and Head for the Architectural Engineering Department at California Polytechnic State University in San Luis Obispo. Until January 2007, Dr. Estes was the Director of the Civil Engineering Program at the United States Military Academy (USMA). He is a registered Professional Engineer in Virginia. Al Estes received a B.S. degree from USMA in 1978, M.S. degrees in Structural Engineering and in Construction Management from Stanford University in 1987 and a Ph.D. degree in Civil Engineering from the University of Colorado at Boulder in 1997. 


\title{
Gender Representation in Architectural Engineering - Is it all in the name?
}

\begin{abstract}
Under-representation of women in engineering is of concern as the decreasing supply of qualified engineers continues to plague the nation's advancement. Understanding what factors influence choices of engineering disciplines has the potential for altering education to accommodate a more diverse student body that can be successful in engineering. University statistics reflect that the Architectural Engineering program at this school is comprised of 35\% women, while the other engineering programs attract at best $20 \%$ women and at worst $5 \%$ women. The Architectural Engineering program at this university is in fact one of the most intense structural engineering programs in the country requiring 203 quarter units to complete and upper division courses in integrated design of buildings using concrete, steel, wood and masonry along with seismic design of buildings. The department is however housed in the College of Architecture and Environmental Design rather than the College of Engineering. This overall research study explores the learning styles of different engineering disciplines and the learning styles preferred by students who select these disciplines as academic majors and careers.

The work in progress centers on surveys of students in engineering programs at this university. A preliminary survey of women in the ARCE department was administered to discover why these women personally chose ARCE as a major, why they persist in the major, and why they think women are so largely represented in the major. A more detailed survey will follow from this work which specifically investigates the three components of the integrated learning style taxonomy - motivation, engagement and learning processes of both women and men in the ARCE department. Future work will investigate other engineering disciplines that represent maximum differential in representation of women from that of ARCE at this university as well as engineering programs at other universities.
\end{abstract}

\section{Introduction}

The study is based on a broad definition of learning style as a combination of learner motivation, engagement and mental processing habits as proposed by Curry ${ }^{1}$. In this research we hypothesize:

- There is a correlation between learning style measures and different engineering disciplines.

- Preferred learning styles are related to engineering discipline selection.

- Learning styles of engineering education and engineering practice both influence gender preference for discipline.

This paper presents the demographic data that initiated the study, documents the results of the preliminary survey and discusses the scope of the more detailed survey to be administered to students in engineering majors. 


\section{Enrollment in Engineering Majors}

Enrollment data for students in engineering majors within the College of Engineering (CENG) and College of Architecture and Environmental Design (CAED) was acquired for the years 2004 to 2008. The total number of students enrolled and the number of women students enrolled is presented in Table 1. Engineering majors are abbreviated as follows: Architectural (ARCE), Aeronautical (AERO), Biomedical (BMED), Civil (CE), Computer (CPE), Computer science (CSC), Electrical (EE), Environmental (ENVE), General (GE), Industrial (IE), Materials (MATE), Mechanical (ME), Manufacturing (MFGE), and Software (SE). This data as well as historical data are presented graphically in Figure 1 for the CENG. Total enrollment data for ARCE is summarized in Figure 2.

Table 1

Female Enrollment by Engineering Major

\begin{tabular}{|c|c|c|c|c|c|c|c|c|c|c|}
\hline Year & \multicolumn{2}{|l|}{2004} & \multicolumn{2}{|l|}{2005} & \multicolumn{2}{|l|}{2006} & \multicolumn{2}{|l|}{2007} & \multicolumn{2}{|l|}{2008} \\
\hline $\begin{array}{l}\text { College } \\
\text { Major }\end{array}$ & Total & Women & Total & Women & Total & Women & Total & Women & Total & Women \\
\hline \multicolumn{11}{|l|}{ CAED } \\
\hline ARCE & 340 & 109 & 340 & 115 & 338 & 121 & 341 & 125 & 305 & 102 \\
\hline \multicolumn{11}{|l|}{ CENG } \\
\hline AERO & 395 & 62 & 424 & 65 & 437 & 62 & 562 & 63 & 534 & 63 \\
\hline BMED & - & - & - & - & 143 & 49 & 338 & 109 & 367 & 121 \\
\hline $\mathbf{C E}$ & 719 & 166 & 759 & 178 & 757 & 171 & 808 & 158 & 769 & 140 \\
\hline CPE & 459 & 36 & 396 & 23 & 426 & 20 & 504 & 33 & 424 & 30 \\
\hline CSC & 510 & 46 & 446 & 34 & 466 & 38 & 458 & 33 & 410 & 34 \\
\hline EE & 769 & 83 & 703 & 58 & 669 & 48 & 647 & 38 & 593 & 41 \\
\hline ENVE & 114 & 42 & 138 & 49 & 116 & 38 & 128 & 45 & 126 & 51 \\
\hline GE & 192 & 47 & 212 & 52 & 193 & 39 & 299 & 58 & 374 & 71 \\
\hline IE & 216 & 60 & 223 & 62 & 233 & 54 & 246 & 57 & 280 & 64 \\
\hline MATE & 115 & 23 & 132 & 21 & 152 & 22 & 174 & 26 & 184 & 30 \\
\hline ME & 1069 & 90 & 1008 & 86 & 965 & 91 & 1006 & 86 & 1013 & 97 \\
\hline MFGE & 73 & 3 & 72 & 4 & 67 & 4 & 68 & 4 & 54 & 1 \\
\hline SE & 47 & 6 & 76 & 10 & 82 & 9 & 66 & 11 & 59 & 9 \\
\hline Total & 4678 & 664 & 4589 & 642 & 4706 & 645 & 5304 & 721 & 5187 & 752 \\
\hline
\end{tabular}




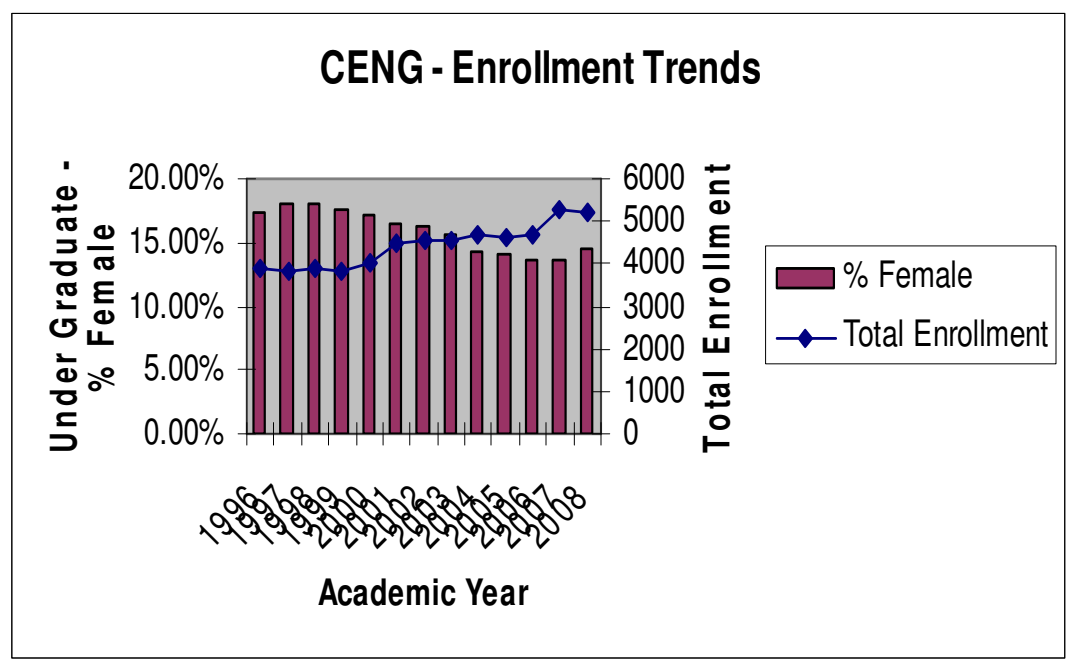

Figure 1. Overall enrollment data for CENG from 1996 to 2008.

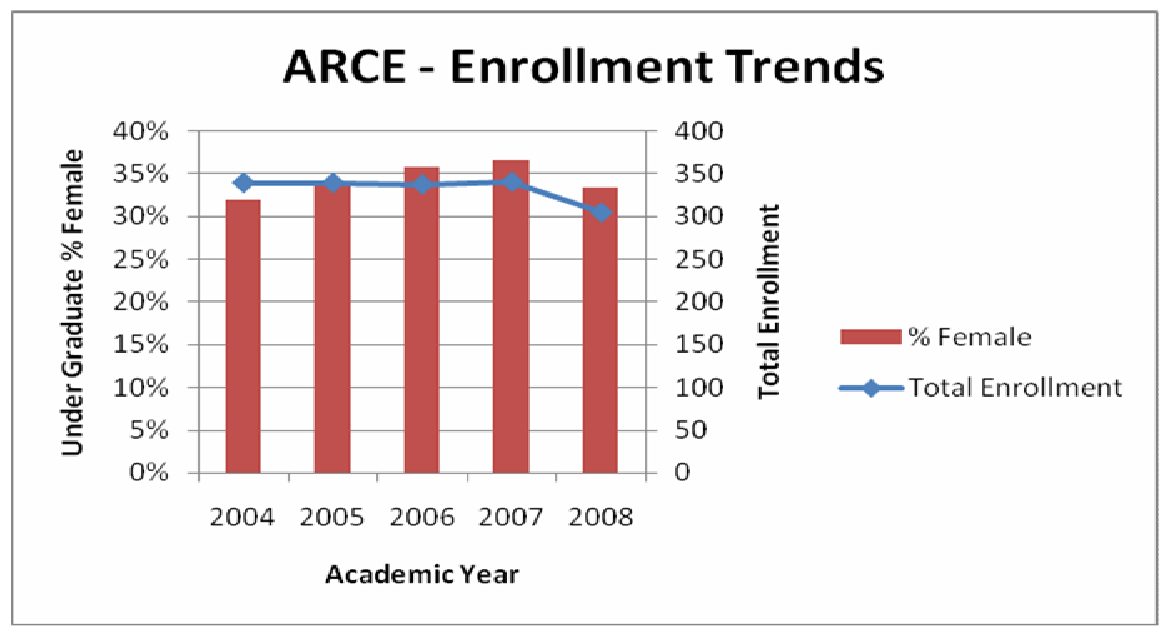

Figure 2. Overall enrollment data for ARCE from 2004 to 2008.

The bars represent the percentage of female enrollment. The line traversing the graph shows that total number of students enrolled in the CENG. The data shows that total enrollment has increased from an average of 4600 students in 2001 to 5300 in 2007 . However, the percentage of female student enrollment has steadily declined from $\sim 17 \%$ in the late 1990s to a leveling in 2006 and 2007 (13.7\% and 13.6\% respectively). There was a slight increase in 2008 to $14.5 \%$; this is the highest percentage enrollment of women since 2003. Majors with the highest percentage of female enrollment are environmental engineering (ENVE) with 41\%, architectural engineering (ARCE) with 33\%, biomedical engineering (BMED) with 33\%, and industrial engineering (IE) with $23 \%$. Majors with the lowest percentage of female enrollment are mechanical engineering (ME) with 10\%, computer science (CSC) at 8\%, electrical engineering 
(EE) with 7\%, and manufacturing engineering (MFG) at 2\%. These trends are consistent with other analyses of women's preference for enrollment in engineering disciplines ${ }^{2}$.

Table 2 presents freshman student enrollment for the same time period. Figures 3 and 4 summarize the data for the CENG and ARCE major emphasizing the percentage of women freshman students with respect to the total freshman enrollment. Total first year enrollment has increased measurably for the last 3 years, spiking in 2007. The percentage of female student enrollment has increased steadily and is at an all time high of 18.2\% in CENG. ARCE major freshman enrollment follows the trends of CENG majors. While ARCE freshman women student enrollment has been high, peaking at $42 \%$, it has decreased in recent years to approximately $30 \%$, still a very significant representation of women students. For most years a higher percentage of females enroll than are represented in the applicant pool.

Table 2

Freshman Women Enrollment by Engineering Major

\begin{tabular}{|c|c|c|c|c|c|c|c|c|c|c|}
\hline Year & \multicolumn{2}{|l|}{2004} & \multicolumn{2}{|l|}{2005} & \multicolumn{2}{|l|}{2006} & \multicolumn{2}{|l|}{2007} & \multicolumn{2}{|l|}{2008} \\
\hline Major & Total & Women & Total & Women & Total & Women & Total & Women & Total & Women \\
\hline \multicolumn{11}{|l|}{ CAED } \\
\hline ARCE & 58 & 22 & 56 & 23 & 58 & 23 & 81 & 24 & 54 & 15 \\
\hline \multicolumn{11}{|l|}{ CENG } \\
\hline AERO & 108 & 15 & 77 & 14 & 129 & 22 & 204 & 21 & 132 & 20 \\
\hline BMED & - & - & - & - & 85 & 30 & 186 & 67 & 79 & 36 \\
\hline $\mathbf{C E}$ & 178 & 43 & 96 & 25 & 126 & 31 & 157 & 26 & 123 & 21 \\
\hline CPE & 91 & 1 & 68 & 1 & 169 & 11 & 209 & 21 & 105 & 11 \\
\hline CSC & 122 & 6 & 74 & 3 & 162 & 13 & 139 & 12 & 91 & 11 \\
\hline EE & 161 & 11 & 98 & 5 & 177 & 9 & 155 & 15 & 74 & 7 \\
\hline ENVE & 37 & 10 & 56 & 21 & 24 & 6 & 40 & 15 & 39 & 19 \\
\hline GE & 61 & 13 & 39 & 11 & 73 & 16 & 183 & 31 & 153 & 30 \\
\hline IE & 39 & 7 & 42 & 12 & 43 & 4 & 47 & 11 & 45 & 11 \\
\hline MATE & 35 & 2 & 37 & 5 & 40 & 3 & 50 & 7 & 45 & 9 \\
\hline ME & 208 & 16 & 166 & 15 & 174 & 16 & 216 & 25 & 190 & 25 \\
\hline MFGE & 15 & 1 & 13 & 1 & 20 & 0 & 17 & 0 & 13 & 0 \\
\hline SE & 23 & 2 & 22 & 4 & 22 & 2 & 14 & 2 & 12 & 0 \\
\hline
\end{tabular}

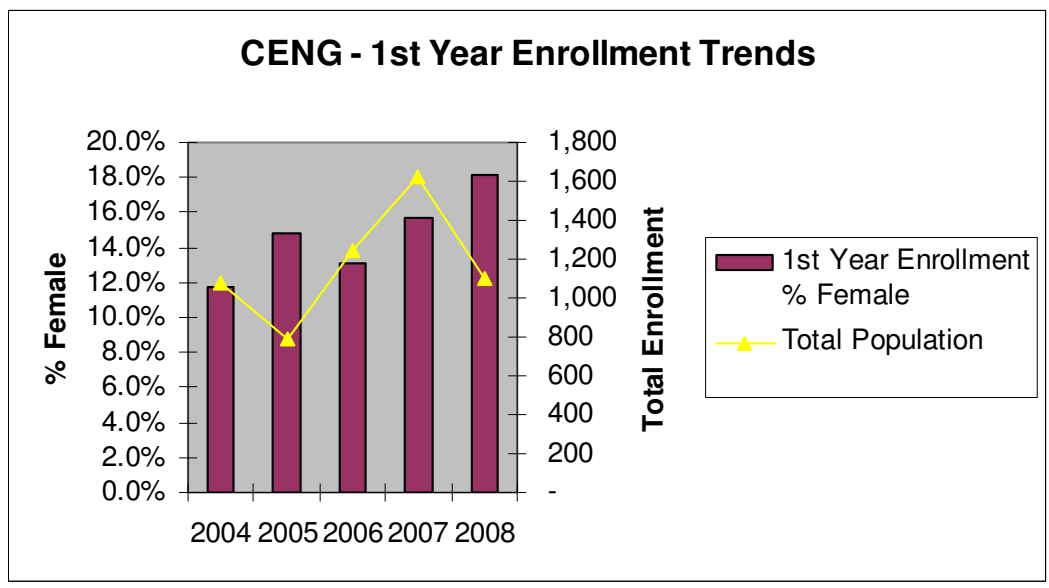


Figure 3. Percentage of women freshman students enrolling in CENG over the last 5 years.

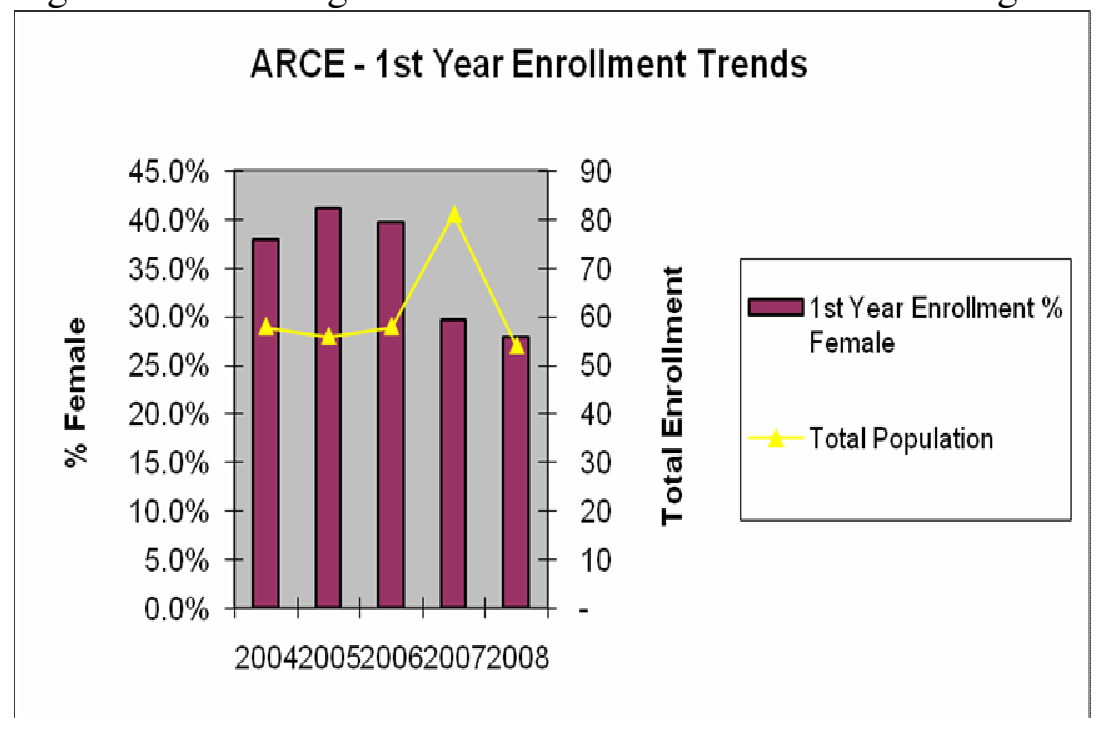

Figure 4. Percentage of women freshman students enrolling in ARCE over the last 5 years.

This data prompts several questions. What is unique about ENVE, ARCE, BMED and IE that they attract 4-6 times the number of female students as ME, CSC, EE, and MFG? Additionally, does the position of ARCE, outside the CENG, afford it any advantage in enrolling women in a technically demanding major or posed in a different manner how important is the relationship of this highly effective structures program to architecture?

\section{Preliminary Survey Results}

To begin to investigate these questions in the spring of 2008 we distributed a brief survey to women students enrolled in the ARCE program at our university. The students were emailed a survey of six questions. In this preliminary survey we sought to have the women students answer general open-ended questions as to why they entered and persisted in the ARCE program. We first identified the class year they held in the program - freshman, sophomore, junior, senior or beyond. We asked - why the student chose the ARCE program and what majors other than ARCE did the student consider, and why the student has stayed in the program. Additionally, we inquired as to why the student thought the percentage of women in ARCE was so much greater than that of other engineering programs? Finally, we encouraged them to suggest questions for a more detailed survey that would get to a better understanding of this representation difference.

A total of 18 women students responded to the survey. They were composed of one freshman, five sophomores, four juniors and eight seniors. In response to the question - "Why did you choose the ARCE program?" - twelve of the 18 students mentioned a strength in math and an interest in art/architecture/buildings. In response to what other majors the student had considered the majority of students (10/18) listed architecture. Eight students had thought of majoring in another engineering field and three had considered majoring in a science. 
In answer to the question - Why did you stay in the ARCE program, even though it is a rigorous structural engineering program? - the responses give a more detailed picture of the students' attraction to the major and department. Several (4/18) commented that the challenge presented by the rigorous program appealed to them. Students stated that they could visualize themselves working in the career (4/18). A number of students expressed that the path opened doors to opportunities beyond ARCE exclusively (5/19). The potential for prestige and money were mentioned as reasons for staying in the program by 4 of 18 students. Four students commented on the comfort they felt with the people - students and teachers- and courses.

As to why they thought the ARCE department had 35\% women in the student population and other engineering programs have a far lesser amount their answers reinforced some of the justifications for choosing and staying in the ARCE program. Half of the students responded that architectural engineering offered a combination of art and engineering. Students also commented that unlike courses in other majors it was normal for there to be women in ARCE and women were respected. Some students also thought that being in a college of architecture and environmental design versus a college of engineering might be less intimidating to women. They commented that stereotypes are not as pervasive and there are is a large representation of women overall in the college; thus, many women may feel more comfortable upon entering the program. Several students commented on the social nature of the program - students are friendly as opposed to competitive with one another and the education involves working in a team with other majors - architecture, and construction management specifically.

The responses from this preliminary survey are aligned with findings from other research indicating women's preferences in learning styles. As previously mentioned learning style is broadly defined as encompassing learner motivation, engagement and cognitive processing habits. Environmental and social conditions influence learner motivation. Learners bring particular processing habits to learning situations. These processes have been identified by researchers in different ways $\left(\mathrm{Kolb}^{3}\right.$, Felder $\left.^{4}\right)$. Engagement links prior experience with the active processing work needed in the new learning environment. It is the convergence of motivation and cognitive processing habits.

Factors influencing ARCE women students' motivation are expressed in their identification of the supportive learning environment they experience. They identify with the major and the environment - both classroom and social, thus affirming their identity. The ways in which they process information are also reinforced in teamwork and multi-disciplinary experiences. They experience engagement in the tasks as their perception of the math skills necessary for the major are used in the new learning environment.

\section{Detailed Survey Plans}

The data also motivate additional and deeper questions regarding learning styles, gender and engineering specialty. Verification of the preliminary results is also required. Additional questions arise with regard to the learning environment - both classroom and extra-curricularwhich may support or detract from women's preference for engineering major. Is the student's perception of necessary math skills the primary determinate for engagement in learning or can 
the breadth of cognitive processing styles required of the major be more clearly defined in relation to women's preferences for learning?

We will seek to answer these questions with further investigation through engineering student inquiry. The next step is to survey women and men students in the ARCE major to discern if both genders are influenced by the proximity of the program within the College of Architecture and Environmental Design versus the College of Engineering. Along with focused questions regarding perceived strengths in technical topics as well as communication and collaboration, existing measures of learning style modes will be used including identify students learning preferences in relation to the major. Possible assessments include the Kolb Learning Style Inventory, Myer-Briggs Type Indicator and Felder 's Index of Learning Styles. We hope to show why students, particularly women students, choose to enter into one engineering discipline over another. We will extend these investigations to other engineering disciplines at our university and other universities.

\section{Bibliography}

1. Curry, Lynn, Educational Psychology, 1991, Vol. 11, Issue 3 / 4.

2. Gibbons, Michael T., 2008. Engineering by the Numbers. http://www.asee.org/publications/profiles/upload/2008ProfileEng.pdf accessed on 12/29/09

3. Kolb, David A., 1981, 'Learning Styles and Disciplinary Differences' in A. W. Chickering (ed.) The Modern American College, San Francisco: Jossey-Bass.

4. Felder, R. and L. Silverman, 1988. Learning and teaching styles in engineering education, Engr. Education, Vol. 78 , Issue 7. 